\title{
Ion-Exchange Chromatographic Method for the Determination of the Free Amino Acid Composition of Cheese and Other Dairy Products: an Inter-Laboratory Validation Study
}

\author{
Johannes A. Hogenboom ${ }^{1}$ • Paolo D'Incecco ${ }^{1}$ • Fabio Fuselli ${ }^{2} \cdot$ Luisa Pellegrino $^{1}$
}

Received: 8 February 2017 / Accepted: 16 March 2017

(C) The Author(s) 2017. This article is published with open access at Springerlink.com

\begin{abstract}
Although free amino acids (FAAs) represent a significant component of ripened cheeses and can provide useful information for their characterization, no inter-laboratory validated analytical method exists which allows a reliable comparison of data obtained by different laboratories and the adoption of quality control schemes based on FAA pattern. The objective of the present work was to test the effectiveness of an analytical protocol for the determination of the FAA composition of cheese and to verify the adequateness of this type of analysis for quality control procedures of Grana Padano PDO cheese as well as for research purposes. After an initial test to compare performances of ion-exchange chromatography (IEC) and HPLC techniques, an inter-laboratory collaborative study (seven laboratories, four samples) was organized to validate an IEC method with post-column ninhydrin derivatization and using L-norleucine as an internal standard. Determined amounts of individual FAA ranged from 8 to over $1380 \mathrm{mg} / 100 \mathrm{~g}$ cheese, with relative standard deviation of repeatability $\left(\mathrm{RSD}_{\mathrm{r}}\right)$ ranging from 0.5 to $4.6 \%$, and relative standard deviation of reproducibility $\left(\mathrm{RSD}_{\mathrm{R}}\right)$ ranging from 1.3 to $9.9 \%$ for FAA concentrations over $100 \mathrm{mg} / 100 \mathrm{~g}$. For lower concentrations, $\mathrm{RSD}_{\mathrm{r}}$ and $\mathrm{RSD}_{\mathrm{R}}$ were about thrice as high. On the basis of the results of this investigation, at present, the validated method is adopted as the official method
\end{abstract}

Johannes A. Hogenboom

john.hogenboom@unimi.it

1 Department of Food, Environmental and Nutritional Sciences (DeFENS), Via G. Celoria 2, 20133 Milan, Italy

2 Ministero delle Politiche Agricole Alimentari e Forestali (MiPAAF) -Direzione Generale delle Politiche Internazionali e dell'Unione Europea (PIUE), Via XX Settembre 20, 00187 Rome, Italy for the determination of FAA patterns in the quality control of Grana Padano PDO cheese.

Keywords Free amino acids $\cdot$ Cheese $\cdot$ Ion-exchange chromatography $\cdot$ Inter-laboratory study $\cdot$ Precision $\cdot$ Method validation

\section{Introduction}

Although free amino acids (FAAs) are usually considered minor cheese constituents, they have been shown to contribute to sensory properties (Toelstede et al. 2009; Zhao et al. 2016), nutritional characteristics (Bottesini et al. 2013), and physiological functions (San Gabriel and Uneyama 2013) of several cheese varieties. During cheese ripening, protein is progressively degraded by a number of proteolytic enzymes including (1) chymosin, (2) indigenous milk proteases, and (3) proteases and peptidases from both starter (LAB) and non-starter lactic acid bacteria (NSLAB), mainly released after cell lysis (Borsting et al. 2012; Gatti et al. 2014). According to the manufacturing process and ripening period, up to $20-25 \%$ of the cheese protein may be split into FAAs, which can represent over 50\% of the soluble $\mathrm{N}$ fraction (Sousa et al. 2001; Pellegrino et al. 2013). In long ripened cheeses, FAA patterns have been investigated as a possible tool for characterizing the ripening process. Whereas some FAAs, such as lysine, alanine, glycine, and serine, are rather stable and mostly accumulate over time (Resmini et al. 1985; Frau et al. 1997), others undergo degradation phenomena through specific metabolic pathways of LAB (Liu et al. 2003; Ardö 2006). Furthermore, some non-protein amino acids (AAs), principally ornithine, citrulline, and $\gamma$-aminobutyric acid, are formed that may represent characteristic traits of certain cheeses (Nomura et al. 
1998; Borsting et al. 2012; Sgarbi et al. 2013; D’Incecco et al. 2016a).

Several Protected Designation of Origin (PDO) cheeses, such as Parmigiano-Reggiano (Resmini et al. 1985), Mahon (Polo et al. 1985), Grana Padano (Resmini et al. 1993; Cattaneo et al. 2008; Masotti et al. 2010), Emmentaler (Krause et al. 1997), Montasio (Innocente 1997), Gruyère and Sbrinz (Bütikofer and Fuchs 1997), and Manchego (Poveda et al. 2004), have been shown to have characteristic FAA patterns. The common rationale behind this fact is that all these cheeses (1) are made from raw milk produced in a restricted geographical area, (2) following a well-defined traditional manufacturing process, and (3) using a natural whey culture daily prepared from the previous cheesemaking. These provisions are detailed in the product specification for PDO protection (European Council 2012) and guarantee that the same relevant microbial species (LAB and NSLAB) are constantly transferred from milk into the cheese (Gatti et al. 2014). As a result, for each cheese type, the proteolytic pathways occurring during ripening are repeatable and hence the resulting FAA pattern as well is repeatable and characteristic. Masotti et al. (2010) determined the FAA pattern of 150 samples of Grana Padano PDO cheese demonstrating that, on the basis of the relative amount of a selected group of FAAs, it is possible to recognize the authentic PDO cheeses from imitation cheeses with high statistical reliability $(p<0.01)$. Due to the power of this analytical approach as a tool for recognizing the authentic PDO cheeses, the respective FAA patterns have been introduced into the product specification among the characteristic traits for both Grana Padano (European Commission 2011a) and Parmigiano-Reggiano (European Commission 2011b).

Several analytical techniques have been proposed for AA determination, principally based on either reversed-phase (RP) HPLC or on ion-exchange chromatography (IEC). Bütikofer and Ardö (1999) demonstrated that the latter technique gives more reliable results in cheese analysis, despite the disadvantage of requiring a dedicated equipment. Since the first time that Moore et al. (1958) proposed the determination of AA by IEC coupled with post-column derivatization with ninhydrin, fully automated instruments have been developed, making this analysis feasible on a routine basis and applicable in research studies in many fields. Despite this, very few methods have been validated at inter-laboratory level (AOAC 1994; European Commission 2009) and, to the author's knowledge, no one dealing with food products. Interlaboratory validated methods allow to compare figures from different studies, provide reliable data to set up quality control schemes, and represent a useful tool for laboratories to assess their own performances.

This paper reports the work conducted to fully validate a method for the determination of the FAA content in cheese that was previously in-house validated and proved to be suitable for cheese characterization. This method includes both the extraction procedure and the chromatographic separation. Several laboratories have been involved, in order to validate it according to the internationally accepted protocols. A total of 21 FAAs were considered, including non-protein amino acids that proved to be present in ripened cheese. A preliminary pilot test was conducted to assess whether HPLC and IEC could give comparable results, and thus, both the techniques could be considered in the validation study. Finally, the suitability of the validated method to control authenticity of Grana Padano PDO cheese was tested using a simple statistical model that we developed in previous studies.

\section{Materials and Methods}

\section{Chemicals}

All reagents, employed for both the FAA extraction and separation, were of analytical grade or higher. L-amino acids were from Sigma-Aldrich (Milan, Italy), except isoleucine from Merck KGaA (Darmstadt, Germany).

\section{Amino Acid Standard Solutions}

For the pilot test, a set of ready-to-use amino acid standards at five different concentrations was prepared at the Department of Food, Environmental and Nutritional Sciences (DeFENS) of the State University of Milan (the coordinating laboratory) and shipped to all participants.

For the collaborative study, a stock solution was prepared at the coordinating laboratory by weighing into a $200-\mathrm{mL}$ volumetric flask:

- $30 \mathrm{mg}$ of $\gamma$-aminobutyric acid (Gaba), citrulline (Cit), glycine (Gly), and glutamine (Gln);

- $40 \mathrm{mg}$ of alanine (Ala), arginine (Arg), asparagine (Asn), methionine (Met), ornithine (Orn), threonine (Thr), and tyrosine (Tyr);

- $60 \mathrm{mg}$ of aspartic acid (Asp), histidine (His), isoleucine (Ile), phenylalanine (Phe), and serine (Ser);

- $80 \mathrm{mg}$ of leucine (Leu), proline (Pro), and valine (Val);

- $90 \mathrm{mg}$ of glutamic acid (Glu) and lysine (Lys)

and making up to the mark with $0.2 \mathrm{~N}$ tri-sodium citrate buffer (SCB) at $\mathrm{pH}$ 2.2. An internal standard solution $(60 \mathrm{mg}$ L- norleucine in $100 \mathrm{~mL} \mathrm{SCB}$ ) was prepared as well. At the participating laboratories, aliquots of $0.5,1,2$, and $5 \mathrm{~mL}$ of the stock AA standard solution were then transferred into $100-\mathrm{mL}$ volumetric flasks, added with $2 \mathrm{~mL}$ of the internal standard solution and made up to the mark with SCB to prepare working solutions at four different concentrations. 


\section{Cheese Samples}

Four samples of Grana Padano PDO cheese (samples A-D) of known age $(9,12,18$, and 22 months) were used for the pilot test. For the validation study, four samples of Grana Padano PDO cheese (samples 1-4) of known age $(6,12,16$, and 20 months) were used. Cheese samples were kindly provided by the Consorzio di Tutela del Formaggio Grana Padano.

All cheeses were sampled according to ISO Standard 707:2008 (ISO 2008), finely ground and thoroughly mixed, then divided into $10 \mathrm{~g}$ portions, sealed under vacuum in small plastic bags, and kept frozen $\left(-32^{\circ} \mathrm{C}\right)$ until shipping. All samples were assigned a serial number (blind samples) before being sent to participants. Samples for the validation study were tested for homogeneity and stability according to the ISO Standard 13528 (ISO 2015).

\section{Organization of the Pilot Test}

Fifteen experienced laboratories participated in a tentative pilot test, seven using IEC with ninhydrin post-column derivatization and eight using reversed-phase HPLC with $o$ phthalaldehyde (OPA) pre-column derivatization. Laboratories were supplied with a set of five AA standards for calibration and were asked to analyze each of twelve cheeses (three blind replicates of four different cheeses), sticking to the protocol for the FAA extraction procedure and using their own chromatographic conditions without any restrictions. Laboratories using HPLC generally adopted a Hypersil ODS column $250 \times 4 \mathrm{~mm}$, a 24-min stepwise linear two-solvent gradient (solvent $\mathrm{A}, 30 \mathrm{mmol} / \mathrm{L} \mathrm{NaOAc}$ $\mathrm{pH} 7.20+0.25 \%$ tetrahydrofurane $+0.1 \mathrm{~mol} / \mathrm{L}$ titriplex III; solvent B: $100 \mathrm{mmol} / \mathrm{L} \mathrm{NaOAc} \mathrm{pH} 7.20+80 \%$ acetonitrile + $0.1 \mathrm{~mol} / \mathrm{L}$ titriplex III), flow rate $1.00 \mathrm{~mL} / \mathrm{min}$, column temperature $42{ }^{\circ} \mathrm{C}$, and fluorescence detection (Ex: $340 \mathrm{~nm}$ and Em: $455 \mathrm{~nm}$ ), as reported by Bütikofer and Ardö (1999).

\section{Organization of the Inter-Laboratory Validation Study}

Seven laboratories participated in the validation study, all experienced in FAA analysis by IEC, and represented government institutions (2), universities (3), and food control laboratories (2).

Table 1 Composition of the elution buffers employed for the separation of free amino acids by the proposed IEC method
Each laboratory was assigned a lab code number, and, prior to the trial, the analyst of each lab participated in a training day where every aspect of the procedure (sample preparation, buffer preparation, FAA extraction, chromatographic separation, peak integration, standard dilution) was discussed and practically carried out.

Besides test samples and the standard stock solution, participants received a protocol of the analytical procedure, a calibration table for the supplied standard, a time schedule, and a report form for the analytical data and comments. A deadline was fixed for data transmission. Participants were asked to perform analyses under repeatability conditions and strictly following the provided protocol.

\section{Protocol for Free Amino Acid Extraction}

The grated cheese is precisely weighted $(1.5 \mathrm{~g})$ in a $100-\mathrm{mL}$ beaker, added with $40-\mathrm{mL}$ SCB, kept under magnetic stirring for $15 \mathrm{~min}$, then carefully homogenized with Ultra-Turrax (5 min at $11000 \mathrm{rpm}$ ). The extract is filtered (Whatman 41 paper filter, GE Healthcare, Milan, Italy), and $10 \mathrm{~mL}$ of the filtrate are transferred into a $25-\mathrm{mL}$ volumetric flask, dropwise added with $10 \mathrm{~mL} 7.5 \%(w / v)$ 5-sulfosalicylic acid (pH 1.71.8) under stirring, kept under stirring for $5 \mathrm{~min}$, diluted to the mark with SCB, and filtered (Whatman 42 paper filter). Finally, $10 \mathrm{~mL}$ of this filtrate are transferred into a $100-\mathrm{mL}$ volumetric flask, added with $2 \mathrm{~mL}$ L- norleucine solution, made up to the mark with $0.2 \mathrm{~N}$ tri-lithium citrate buffer at pH 2.2 (LCB), and filtered on $0.2-\mu \mathrm{m}$ regenerated cellulose filter (Minisart® RC 25, Sartorius, Goettingen, Germany) prior to injection.

\section{Protocol for the Determination of Free Amino Acids by Ion-Exchange Chromatography}

Six different elution buffers are employed; buffer composition is indicated in Table 1. All buffers, except buffer 6, are added with $0.1 \mathrm{~mL} / \mathrm{L}$ of pentachlorophenol $(500 \mathrm{mg} / 100 \mathrm{~mL}$ ethanol) as a preservative; buffers 1,2 , and 3 are added with $8.0 \mathrm{~mL} / \mathrm{L}$ of a $25 \%(\mathrm{v} / \mathrm{v})$ thiodiglycol water solution and buffers 1 and 2 with $15 \mathrm{~mL} / \mathrm{L}$ of isopropyl alcohol.

\begin{tabular}{lllll}
\hline & Lithium hydroxide $\cdot \mathrm{H}_{2} \mathrm{O}(\mathrm{g} / \mathrm{L})$ & Citric acid $(\mathrm{g} / \mathrm{L})$ & Lithium chloride $(\mathrm{g} / \mathrm{L})$ & $\mathrm{pH}$ \\
\hline Buffer 1 & 8.40 & 9.60 & - & 2.80 \\
Buffer 2 & 8.40 & 9.60 & 4.25 & 3.00 \\
Buffer 3 & 8.40 & 9.60 & 12.72 & 3.15 \\
Buffer 4 & 4.20 & 9.60 & 34.00 & 3.50 \\
Buffer 5 & 7.00 & 21.00 & 61.50 & 3.58 \\
Buffer 6 & 12.59 & - & - & - \\
\hline
\end{tabular}


Table 2 Chromatographic conditions for the separation of free amino acids by the proposed IEC method

\begin{tabular}{llllll}
\hline Step & Duration & Temperature $\left({ }^{\circ} \mathrm{C}\right)$ & Buffer & Flow rate $(\mathrm{mL} / \mathrm{h})$ & Ninhydrin \\
\hline 1 & $01: 00$ & 32 & 1 & 20 & On \\
2 & $01: 00$ & 32 & 1 & 20 & On \\
3 & $01: 00$ & 32 & 1 & 20 & On \\
4 & $05: 30$ & 32 & 1 & 20 & On \\
5 & $43: 00$ & 32 & 2 & 20 & On \\
6 & $17: 00$ & 40 & 3 & 20 & On \\
7 & $10: 00$ & 64 & 3 & 20 & On \\
8 & $34: 00$ & 64 & 4 & 20 & On \\
9 & $50: 00$ & 76 & 5 & 20 & On \\
10 & $06: 00$ & 76 & 6 & 20 & On \\
11 & $10: 00$ & 32 & 1 & 20 & On \\
12 & $01: 00$ & 32 & 1 & Off & Off \\
13 & $25: 00$ & 32 & 1 & 25 & Off \\
14 & $10: 00$ & 32 & 1 & 20 & On \\
End & & & & & \\
\hline
\end{tabular}

FAAs are separated using the gradient of $\mathrm{pH}$, ionic strength, and temperature reported in Table 2; ninhydrin flow rate is $20.0 \mathrm{~mL} / \mathrm{h}$. Injection volume is $100 \mu \mathrm{L}$.

\section{Statistical Analysis}

Results obtained in the pilot study were evaluated by calculating mean values and relative standard deviations (RSDs) for every single FAA determined in all four samples both by IEC and by HPLC. Significant differences between data obtained by the two techniques were detected by Student's $t$ test. Statistical evaluation of the data of the collaborative study and calculation of the precision figures (means, standard deviation and relative standard deviation of repeatability and of reproducibility, repeatability, and reproducibility limits) were carried out according to ISO Standard 5725 (ISO 2004). Detection of outliers was performed by Cochran's $C$ test for abnormal variances and Grubbs' test for abnormal mean values.

\section{Results and Discussion}

\section{Pilot Test}

The mean values of the total content of the 17 FAA determined in the four test samples were comparable between the two techniques, but variability was much higher for HPLC data (Fig. 1). Overall, contents of individual FAAs approximately ranged from $50 \mathrm{mg} / 100 \mathrm{~g}$ cheese (glutamine and
Fig. 1 Mean values and ranges of total free amino acid (FAA) content $\left(\mathrm{mg} / 100 \mathrm{~g}\right.$ cheese. $\left.10^{-3}\right)$ in four cheese samples analyzed by IEC and HPLC

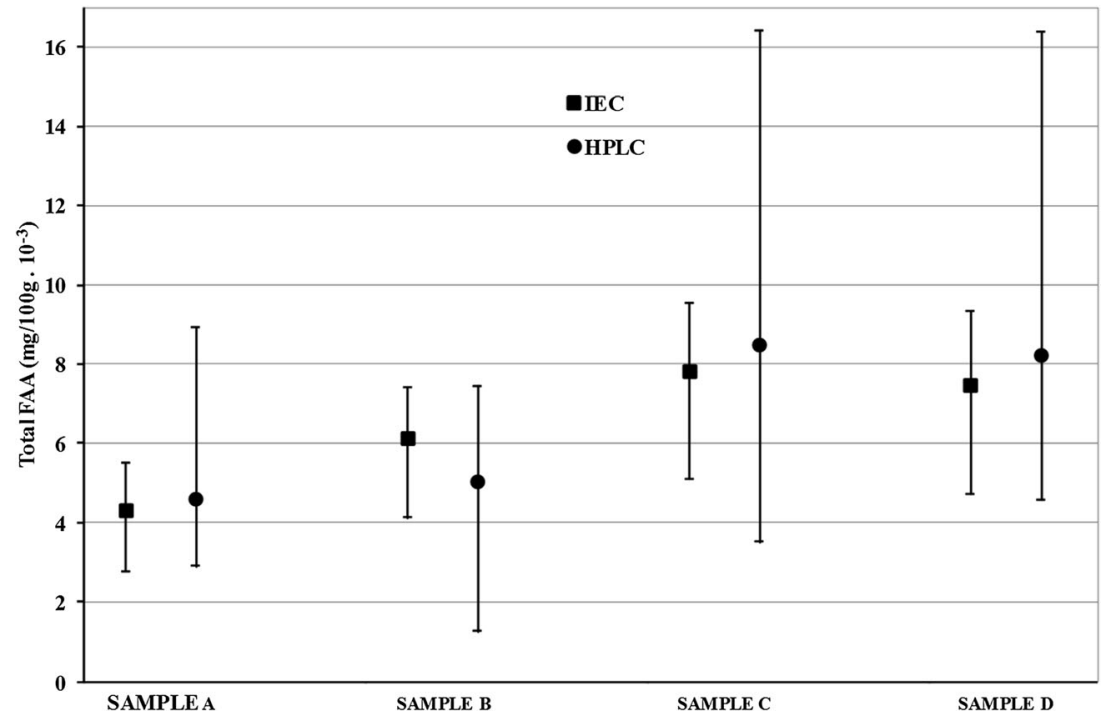


Table 3 Mean value and RSD \% of individual FAA content in four cheese samples analyzed by IEC and HPLC

\begin{tabular}{|c|c|c|c|c|c|c|c|c|c|}
\hline & & \multicolumn{2}{|c|}{ Sample A } & \multicolumn{2}{|c|}{ Sample B } & \multicolumn{2}{|c|}{ Sample C } & \multicolumn{2}{|c|}{ Sample D } \\
\hline & & IEC & HPLC & IEC & HPLC & IEC & HPLC & IEC & HPLC \\
\hline \multirow[t]{3}{*}{ Asp } & Mean & 103 & 89 & 182 & 158 & 340 & 311 & 351 & 338 \\
\hline & RSD \% & 37 & 37 & 23 & 38 & 16 & 36 & 23 & 34 \\
\hline & $p<0.05$ & & & & & & & & \\
\hline \multirow[t]{3}{*}{ Thr } & Mean & 127 & 163 & 217 & 223 & 206 & 401 & 190 & 343 \\
\hline & RSD \% & 20 & 48 & 18 & 37 & 17 & 72 & 18 & 66 \\
\hline & $p<0.05$ & * & & & & $*$ & & $*$ & \\
\hline \multirow[t]{3}{*}{ Ser } & Mean & 165 & 200 & 308 & 272 & 427 & 510 & 480 & 592 \\
\hline & RSD \% & 24 & 41 & 17 & 37 & 17 & 33 & 20 & 31 \\
\hline & $p<0.05$ & * & & & & $*$ & & $*$ & \\
\hline \multirow[t]{3}{*}{ Asn } & Mean & 140 & 235 & 201 & 252 & 189 & 336 & 155 & 284 \\
\hline & RSD \% & 30 & 33 & 30 & 35 & 28 & 38 & 34 & 35 \\
\hline & $p<0.05$ & * & & * & & $*$ & & * & \\
\hline \multirow[t]{3}{*}{ Glu } & Mean & 690 & 711 & 1000 & 803 & 1474 & 1487 & 1442 & 1508 \\
\hline & RSD \% & 19 & 32 & 19 & 35 & 25 & 36 & 27 & 36 \\
\hline & $p<0.05$ & & & $*$ & & & & & \\
\hline \multirow[t]{3}{*}{ Gln } & Mean & 171 & 219 & 115 & 131 & 48 & 94 & 132 & 65 \\
\hline & RSD \% & 19 & 15 & 31 & 36 & 17 & 60 & 13 & 22 \\
\hline & $p<0.05$ & $*$ & & & & & & & \\
\hline \multirow[t]{3}{*}{ Gly } & Mean & 97 & 134 & 142 & 120 & 229 & 283 & 217 & 283 \\
\hline & RSD \% & 29 & 57 & 22 & 46 & 18 & 74 & 24 & 68 \\
\hline & $p<0.05$ & $*$ & & & & & & & \\
\hline \multirow[t]{3}{*}{ Ala } & Mean & 117 & 160 & 176 & 157 & 221 & 194 & 201 & 181 \\
\hline & RSD \% & 29 & 65 & 22 & 39 & 19 & 45 & 22 & 42 \\
\hline & $p<0.05$ & $*$ & & & & & & & \\
\hline \multirow[t]{3}{*}{ Val } & Mean & 281 & 338 & 440 & 386 & 565 & 652 & 533 & 686 \\
\hline & RSD \% & 19 & 50 & 17 & 34 & 17 & 52 & 19 & 50 \\
\hline & $p<0.05$ & & & & & & & $*$ & \\
\hline \multirow[t]{3}{*}{ Met } & Mean & 130 & 110 & 160 & 133 & 204 & 231 & 195 & 218 \\
\hline & RSD \% & 64 & 44 & 38 & 34 & 32 & 36 & 33 & 31 \\
\hline & $p<0.05$ & & & & & & & & \\
\hline \multirow[t]{3}{*}{ Ile } & Mean & 242 & 293 & 387 & 355 & 495 & 626 & 467 & 596 \\
\hline & RSD \% & 25 & 52 & 17 & 31 & 17 & 49 & 18 & 46 \\
\hline & $p<0.05$ & & & & & & & $*$ & \\
\hline \multirow[t]{3}{*}{ Leu } & Mean & 398 & 440 & 558 & 496 & 651 & 757 & 593 & 697 \\
\hline & RSD \% & 16 & 28 & 16 & 35 & 19 & 34 & 18 & 30 \\
\hline & $p<0.05$ & & & & & & & $*$ & \\
\hline \multirow[t]{3}{*}{ Tyr } & Mean & 130 & 137 & 148 & 114 & 148 & 154 & 156 & 139 \\
\hline & RSD \% & 45 & 75 & 35 & 41 & 34 & 57 & 36 & 67 \\
\hline & $p<0.05$ & & & & & & & & \\
\hline \multirow[t]{3}{*}{ Phe } & Mean & 215 & 227 & 317 & 266 & 403 & 441 & 371 & 411 \\
\hline & RSD \% & 22 & 26 & 17 & 34 & 14 & 26 & 16 & 23 \\
\hline & $p<0.05$ & & & & & & & & \\
\hline \multirow[t]{3}{*}{ Lys } & Mean & 461 & 622 & 684 & 686 & 885 & 1257 & 845 & 1247 \\
\hline & RSD \% & 19 & 48 & 19 & 37 & 21 & 50 & 22 & 50 \\
\hline & $p<0.05$ & $*$ & & & & $*$ & & $*$ & \\
\hline \multirow[t]{2}{*}{ His } & Mean & 173 & 178 & 183 & 147 & 237 & 301 & 209 & 204 \\
\hline & RSD \% & 31 & 39 & 29 & 36 & 22 & 47 & 58 & 41 \\
\hline
\end{tabular}


Table 3 (continued)

\begin{tabular}{|c|c|c|c|c|c|c|c|c|c|}
\hline & & \multicolumn{2}{|c|}{ Sample A } & \multicolumn{2}{|c|}{ Sample B } & \multicolumn{2}{|c|}{ Sample C } & \multicolumn{2}{|c|}{ Sample D } \\
\hline & & IEC & HPLC & IEC & HPLC & IEC & HPLC & IEC & HPLC \\
\hline & $p<0.05$ & & & & & $*$ & & & \\
\hline \multirow[t]{3}{*}{ Arg } & Mean & 249 & 229 & 221 & 159 & 51 & 186 & 134 & 250 \\
\hline & $\mathrm{RSD} \%$ & 30 & 20 & 34 & 29 & 109 & 160 & 56 & 129 \\
\hline & $p<0.05$ & & & $*$ & & $*$ & & & \\
\hline
\end{tabular}

Raw FAA data are expressed as $\mathrm{mg} / 100 \mathrm{~g}$ cheese

arginine in sample C) to $1500 \mathrm{mg} / 100 \mathrm{~g}$ cheese (glutamic acid in samples B and D), demonstrating the presence of FAAs over a very wide range of concentrations (Table 3 ). On average, data obtained by IEC were about $7 \%$ lower than those obtained by HPLC, but were significantly less variable. For many individual FAAs, RSD values for HPLC data were almost twice as high as those for IEC. The higher variability of HPLC data is probably due to the instability of some OPAamino acid derivatives (Heems et al. 1998). As an additional drawback, OPA reacts only with primary amines and hence does not allow detection of proline, which represents 8-10\% of FAA in cheese. Due to these disadvantages and considering that concentrations of several FAA were significantly different $(p<0.05)$ between the two techniques (Table 3$)$, it was decided to perform the validation study only for the IEC method. A thorough investigation of the operating conditions of the seven laboratories using the IEC method and involved in the pilot test evidenced some relevant discrepancies in their calibration lines. As an example, calibration lines obtained for glutamine are shown in Fig. 2. The slope of calibration lines obtained by labs 2, 4, and 5 were very similar, and steeper than those of labs 3, 7, and 8. As a matter of fact, labs 3 and 8 were using instruments with poorly performing detectors and were asked to improve this aspect. Unexpectedly, lab 7 used an HPLCIEC hybrid equipment, in-house modified for post-column derivatization with ninhydrin and, due to low sensitivity of the apparatus, doubled the concentration of standard solutions. This lab was excluded from participating to the validation study and replaced by another one. Furthermore, lab 6 used an injection volume of $20 \mu \mathrm{L}$ (instead of $100 \mu \mathrm{L}$ used at the other labs), resulting in very small, difficult to integrate peaks, and systematically produced the lowest data. This lab was invited to follow the provided protocol.

\section{Laboratory Training}

Prior to the collaborative study, a training day was organized for all participants, where the analytical procedure was shown and main critical steps were discussed. The major critical point was poor separation of partly overlapping peaks of asparagine, glutamic acid, and glutamine that could make the integration troublesome. Glutamic acid is more sensitive than asparagine and glutamine to changes in $\mathrm{pH}$ and elutes earlier when $\mathrm{pH}$ slightly increases. Optimum resolution is most easily obtained by adjusting the $\mathrm{pH}$ of eluting buffer 1 by $0.01-0.02$ units. A typical IEC chromatogram of an amino acid standard is shown
Fig. 2 Calibration lines of glutamine obtained by IEC at different laboratories

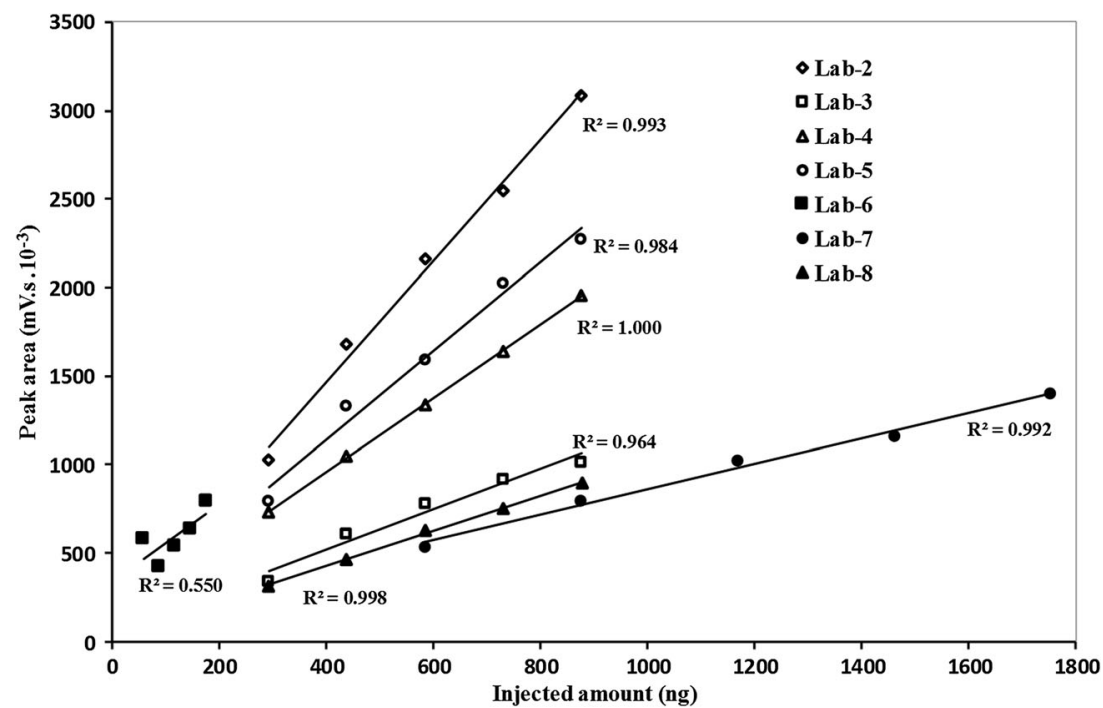


in Fig. 3, which also highlights a situation of poor peak resolution for the three mentioned FAA. It was furthermore necessary to substitute the isoleucine in the standard solution with one from a different producer, as the original gave a double peak in the chromatogram (not shown). All laboratories were informed about these aspects and requested to adopt decisive measures.

\section{Homogeneity and Stability Tests}

All the test samples passed the homogeneity and stability tests, carried out according to ISO Standard 13528:2015 (ISO 2015). Threshold values exceeding 0.3 were observed for tyrosine in samples 3 and 4, where its concentration was highest, probably because of the low solubility of this AA, which tends to crystallize in ripened cheeses (Tansman et al. 2015; D’Incecco et al. 2016b).

\section{Inter-Laboratory Validation Study}

Participants were asked to perform 12 determinations (three blind replicate analyses of four different cheese samples), in the minor possible lapse of time, and to return, together with their data, all of the obtained chromatograms, in order to detect problems which possibly occurred in separation. All laboratories were able to achieve optimal peak resolution and obtained calibration lines having $R^{2}>0.997$ for every FAA.

Statistical evaluation of the data and calculation of precision figures were carried out according to the internationally accepted procedures (ISO 2004) and are reported in Table 4. Considering the small number of participating laboratories, a 0.01 confidence level was adopted. In no case more than one laboratory was eliminated from the evaluation for the same FAA in the same sample; therefore, data from at least six laboratories were evaluated for every single amino acid in every single sample. Only $2 \%$ of the data were outliers and thus excluded from statistical evaluation. On the whole, these figures revealed a significant improvement if compared with those obtained in the pilot test (Table 3). This was the result of (1) availability of correctly performing equipment at all participating laboratories, (2) practical training, highlighting the critical points of the procedure, (3) strict application of the protocol, and (4) adoption of an internal standard.

The total amount of FAA determined in the four samples ranged between approx. 5500 and $8000 \mathrm{mg} / 100 \mathrm{~g}$ cheese, with a maximum relative standard deviation of repeatability $\left(\mathrm{RSD}_{\mathrm{r}}\right)$ value of 2.7 and a maximum relative standard deviation of reproducibility $\left(\mathrm{RSD}_{\mathrm{R}}\right)$ value of 5.6.

The mean content of single FAAs ranged from $8 \mathrm{mg} / 100 \mathrm{~g}$ (ornithine in sample 1) to $1380 \mathrm{mg} / 100 \mathrm{~g}$ (glutamic acid in sample 3), with a ratio which approximates 1:200. In about $75 \%$ of the cases, the average content of single FAAs fell in the range from 100 to $700 \mathrm{mg} / 100 \mathrm{~g}$. The $\mathrm{RSD}_{\mathrm{r}}$ values were lower than 2.0 for 49 out of the 84 determined single FAA contents $(58 \%)$. $\mathrm{RSD}_{\mathrm{r}}$ values exceeding 5.0 were observed only for FAAs present in the lowest amounts, i.e., glutamine, $\gamma$-aminobutyric acid, ornithine, or arginine. Indeed, these FAAs represent reagents or products of specific metabolic pathways of some LAB species, and their content gives interesting information (D'Incecco et al. 2016a; Brasca et al. 2016). $\mathrm{RSD}_{\mathrm{r}}$ values exceeding 5.0 were also observed for tyrosine, whose high $\mathrm{RSD}_{\mathrm{r}}$ values (sample 2 and sample 3) (already observed during the homogeneity test) are most likely

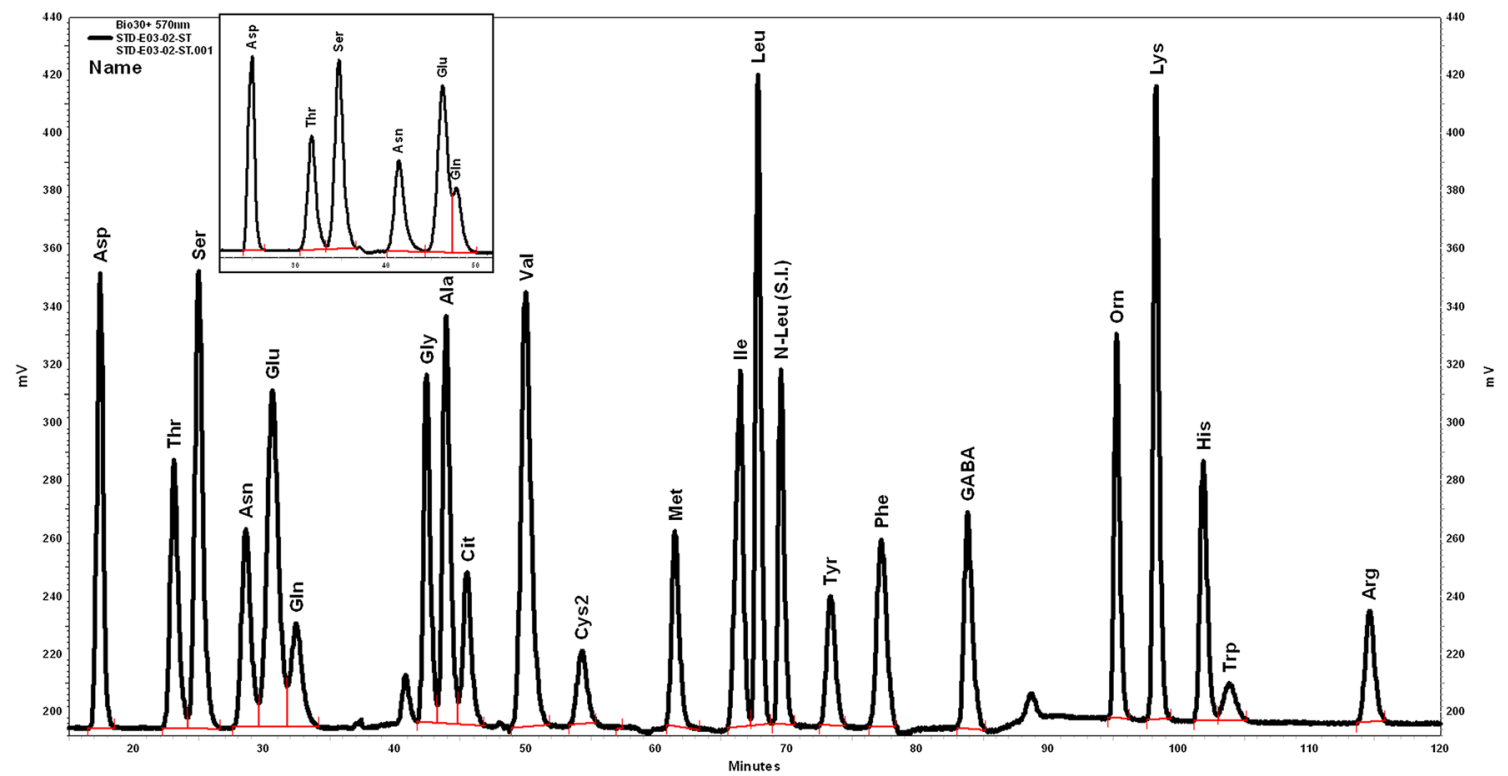

Fig. 3 IEC chromatogram of an amino acid standard and example of poor Glu/Gln resolution (box) due to low buffer $\mathrm{pH}$ 
क $\infty$

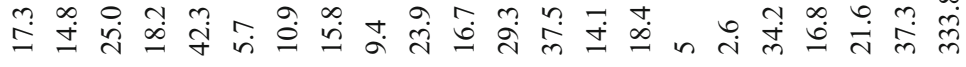
요

氙

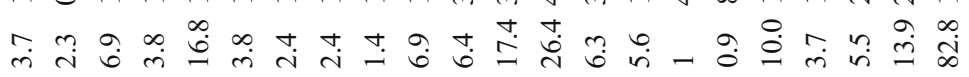

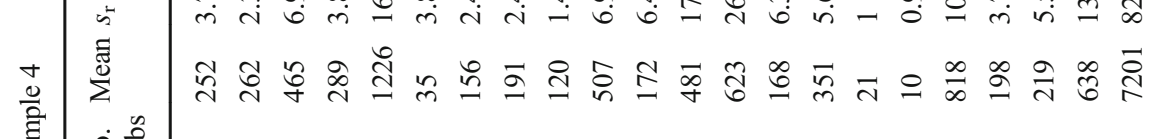

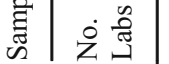

\& 髉

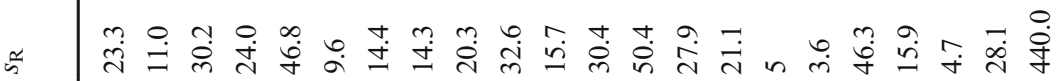
- I 웅

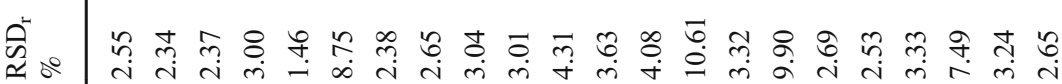

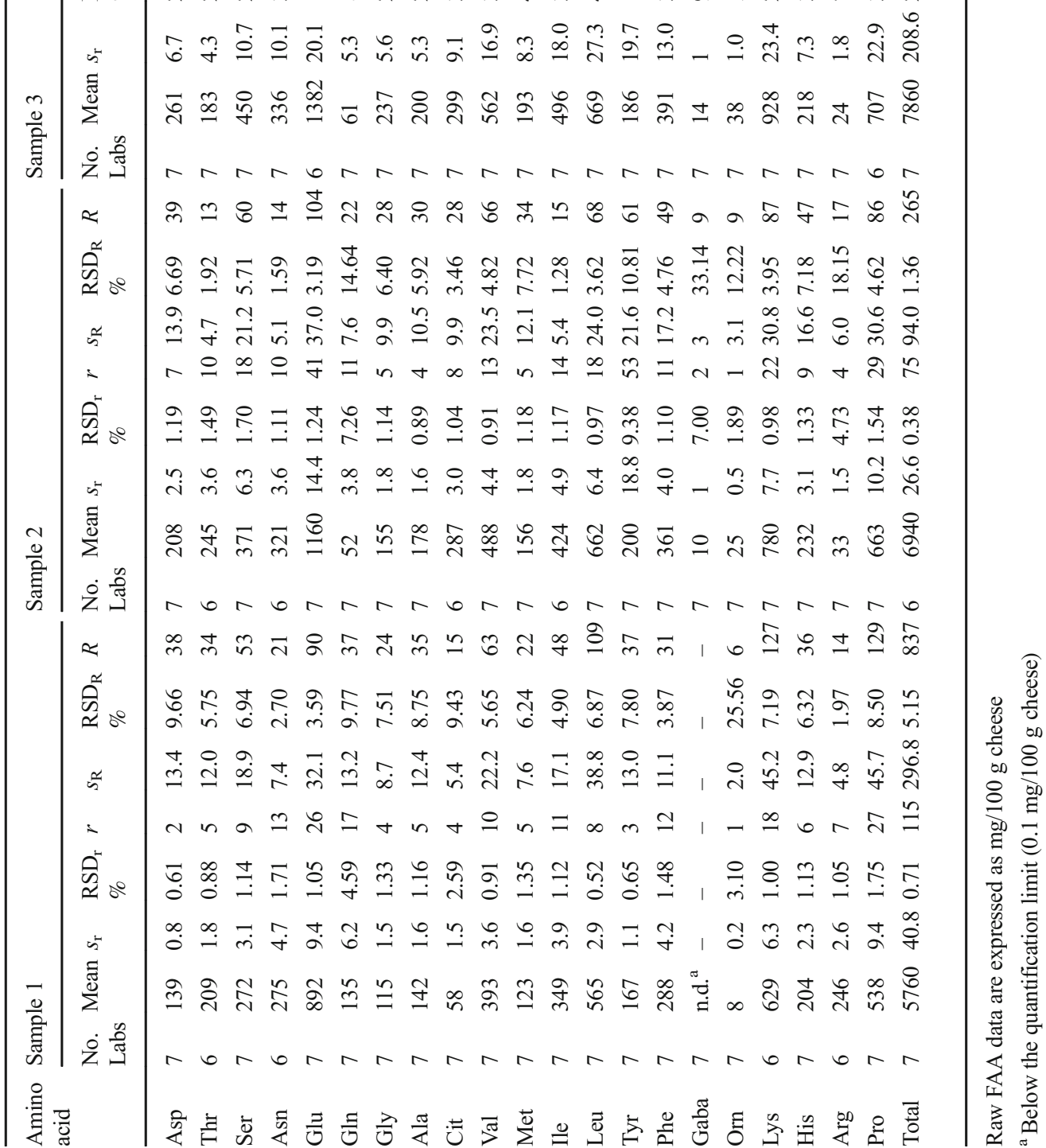


due to the low solubility of this AA, which is known to appear as white crystals in many types of ripened cheeses (Tansman et al. 2015; D'Incecco et al. 2016b).

For 71 out of the 84 determined single FAA contents $(85 \%)$, the $\mathrm{RSD}_{\mathrm{R}}$ values were lower than 10.0 , and values exceeding this level all referred to the same FAA with the lowest amounts above mentioned.

To further evaluate the results of the collaborative study, the obtained $\mathrm{RSD}_{\mathrm{R}}$ values were compared to those calculated by applying the Horwitz equation (Horwitz et al. 1980). For numerous analytes, a relationship exists between the measured mean concentration and its variability $\left(\mathrm{RSD}_{\mathrm{R}}\right)$, expressed by the equation:

$$
\mathrm{PRSD}_{\mathrm{R}}=2^{(1-0.5 \log C)}
$$

Equivalent to

$$
\mathrm{PRSD}_{\mathrm{R}}=2 C^{-0.15}
$$

where $C$ is the concentration of the analyte expressed as dimensionless mass fraction and $\mathrm{PRSD}_{\mathrm{R}}$ is the relative standard deviation under reproducibility conditions.

From this equation derives the Horwitz ratio (HorRat) (Horwitz and Albert 2006), which is the ratio of the $\mathrm{RSD}_{\mathrm{R}}$ calculated from the test data to the predicted $\mathrm{RSD}_{\mathrm{R}}\left(\mathrm{PRSD}_{\mathrm{R}}\right)$ obtained by the Horwitz equation (2):

HorRat $=\mathrm{RSD}_{\mathrm{R}} / \mathrm{PRSD}_{\mathrm{R}}$

Under reproducibility conditions, HorRat values range between 0.5 and 2.0 (Horwitz and Albert 2006). Only in 12 out of 84 cases the HorRat values calculated for single FAAs in the four samples of this study (Table 5) exceeded the value of two, all referring to concentrations below $50 \mathrm{mg} / 100 \mathrm{~g}$, and in $7 \mathrm{of}$ these cases, HorRat did not reach the value of 3.0. The precision figures obtained in the present investigation are fully comparable to those reported in the AOAC Official Method 1994.12 (AOAC 1994) as well as to those indicated in Reg. (EC) No 152/2009 (European Commission 2009) for the determination of free lysine, methionine, and threonine in feeding stuffs.

As one of the aims of this study was to verify the possibility of applying the proposed IEC method to the quality control of different cheese types, the reliability of the proposed method was further checked by testing the capability to recognize authentic Grana Padano PDO cheese. The FAA data obtained for the test samples were evaluated according to a chemometric model we have recently developed for the characterization of Grana Padano PDO cheese. This model compares the relative content (i.e., expressed as percentage of total FAAs) of every single FAA of a cheese to the typical value,
Table 5 HorRat values for individual FAA determined by IEC within the validation study

\begin{tabular}{lllll}
\hline Amino acid & Sample 1 & Sample 2 & Sample 3 & Sample 4 \\
\hline Asp & 1.795 & 1.321 & 1.656 & 1.396 \\
Thr & 1.136 & 0.389 & 1.128 & 1.157 \\
Ser & 1.426 & 1.230 & 1.404 & 1.199 \\
Asn & 0.555 & 0.334 & 1.483 & 1.307 \\
Glu & 0.883 & 0.815 & 0.842 & 0.890 \\
Gln & 1.807 & 2.307 & 2.572 & 2.462 \\
Gly & 1.357 & 1.208 & 1.163 & 1.324 \\
Ala & 1.630 & 1.142 & 1.381 & 1.610 \\
Cit & 1.535 & 0.716 & 1.413 & 1.418 \\
Val & 1.227 & 1.082 & 1.306 & 0.378 \\
Met & 1.138 & 0.556 & 1.537 & 1.863 \\
Ile & 1.046 & 0.282 & 1.289 & 1.364 \\
Leu & 1.575 & 0.851 & 1.683 & 1.401 \\
Tyr & 1.747 & 2.121 & 2.783 & 1.604 \\
Phe & 0.802 & 1.022 & 1.120 & 1.120 \\
Gaba & n.d. ${ }^{\mathrm{a}}$ & 4.143 & 4.269 & 3.189 \\
Orn & 3.091 & 1.757 & 1.443 & 3.231 \\
Lys & 1.609 & 0.951 & 1.114 & 1.014 \\
His & 1.245 & 1.440 & 1.395 & 1.662 \\
Arg & 0.398 & 2.713 & 2.755 & 1.961 \\
Pro & 1.935 & 1.087 & 0.874 & 1.365 \\
Total & 1.745 & 0.455 & 1.835 & 1.560 \\
\hline Below & & & & \\
\hline
\end{tabular}

${ }^{\mathrm{a}}$ Below the quantification limit $(0.1 \mathrm{mg} / 100 \mathrm{~g}$ cheese)

determined as the mean content in a set of 260 Grana Padano PDO samples of known age and origin. The differences between actual and expected values are expressed as $Z$-scores (number of standard deviations). In genuine Grana Padano PDO cheese, $Z$-score may exceed the value of 2.0 for a maximum of four single FAA, whereas only for one of these $Z$-score may exceed 3.0.

Figure 4 shows the evaluation of the data obtained at the participating laboratories for samples 1 and 3 according to the previously described model. The central solid line $(Z$-score $=0)$ indicates the typical mean value for each FAA, circles represent the average $Z$-score observed at the seven labs, and whiskers the range of variability. Sample 1, although produced adopting the traditional manufacturing process, was correctly recognized as a not authentic cheese, since it had not reached the minimum ripening period of 9 months. In fact, all laboratories certified $Z$-scores over 2.0 for at least five different amino acids, all labs finding high contents for glutamine; asparagine and arginine, typical of young Grana Padano cheeses; and low values for glutamic and aspartic acid. On the contrary, sample 3 was recognized as a genuine Grana Padano PDO by all participating laboratories, since only for 
Fig. 4 Evaluation of the FAA composition of Grana Padano test sample 1 (6-month-old (a)) and sample 3 (16-month-old (b)) according to the chemometric model for characterizing Grana Padano PDO cheese
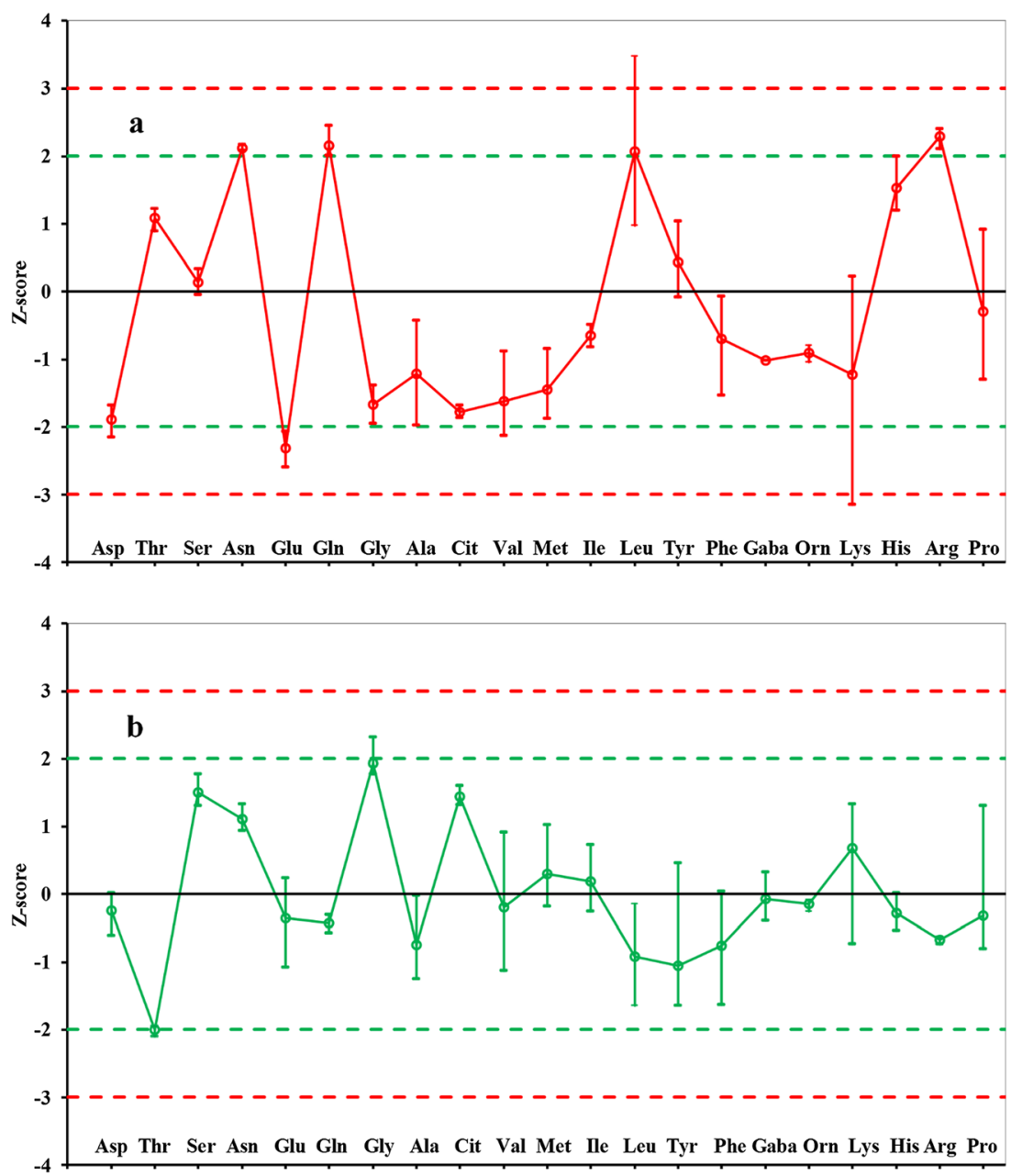

two FAAs (threonine and glycine) values just beyond the 2.0 $Z$-score limit were observed in a few laboratories.

\section{Conclusions}

The information achieved by determining 22 variables in a single analysis makes the evaluation of FAAs in cheese a powerful tool for studying the ripening and fermentation mechanisms and may allow to verify the authenticity of some PDO cheeses. However, analytical methods proposed so far for FAA determination by IEC have been validated at intralaboratory level only, usually by evaluating day-to-day repeatability, making it difficult or even impossible to compare data from different labs. We have optimized a method for the determination of relevant FAAs in cheese, and the interlaboratory study carried out to validate this method has demonstrated its adequacy for the quality control of cheese. The influence of instrumentation performances has been highlighted as well as the need for strict application of the analysis protocol to obtain reliable data.
On the basis of the results of this investigation, the validated method is currently applied for the determination of FAA patterns in the control of Grana Padano PDO cheese identity. We have recently adopted the proposed method for the FAA determination in other dairy products, including milk, fermented milk, infant formulae, milk-based beverages, and whey cultures, and proved it to be free of interference and to give the same performances as for cheese.

Acknowledgements The authors wish to thank the following labs for their collaboration to the method validation study: Innovhub-SSI Div. SSOG, Milan, Italy; Dipartimento dell'Ispettorato Centrale della Qualità e della Repressione Frodi dei Prodotti Agroalimentari, Laboratorio di Perugia e Laboratorio di Roma, Italy; Chelab Silliker, Resana (TV), Italy; Dipartimento Agricoltura, Ambiente e Alimenti, Università del Molise, Campobasso, Italy; Dipartimento di Scienze della Vita, Seconda Università di Napoli, Naples, Italy.

\section{Compliance with Ethical Standards}

Conflict of Interest Johannes A. Hogenboom declares that he has no conflict of interest.

Paolo D'Incecco declares that he has no conflict of interest. 
Fabio Fuselli declares that he has no conflict of interest.

Luisa Pellegrino declares that she has no conflict of interest.

Funding This study did not receive any funding.

Ethical Approval This article does not contain any studies with human participants or animals performed by any of the authors.

Informed Consent Not applicable.

Open Access This article is distributed under the terms of the Creative Commons Attribution 4.0 International License (http:// creativecommons.org/licenses/by/4.0/), which permits unrestricted use, distribution, and reproduction in any medium, provided you give appropriate credit to the original author(s) and the source, provide a link to the Creative Commons license, and indicate if changes were made.

\section{References}

Ardö Y (2006) Flavour formation by amino acid catabolism. Biotechnol Adv 24:238-242

Association of Official Analytical Chemists (1994) AOAC Official Method 994.12 — amino acids in feeds. J AOAC Int 77:1362-1372

Borsting MW, Qvist KB, Rasmussen M, Vindelov J, Vogense F, Ardö Y (2012) Impact of selected coagulants and starters on primary proteolysis and amino acid release related to bitterness and structure of reduced-fat Cheddar cheese. Dairy Sci Technol 92:593-612

Bottesini C, Paolella S, Lambertini F, Galaverna G, Tedeschi T, Dossena A, Marchelli R, Sforza S (2013) Antioxidant capacity of water soluble extracts from Parmigiano-Reggiano cheese. Int J Food Sci Nutr 64:953-958

Brasca M, Hogenboom JA, Morandi S, Rosi V, D'Incecco P, Silvetti T, Pellegrino L (2016) Proteolytic activity and production of $\gamma$ aminobutyric acid by streptococcus thermophilus cultivated in microfiltered pasteurized milk. J Agric Food Chem 64:86048614

Bütikofer U, Ardö Y (1999) Quantitative determination of free amino acids in cheese. International Dairy Federation (IDF) Bulletin 337: 24-32

Bütikofer U, Fuchs D (1997) Development of free amino acids in Appenzeller, Emmentaler, Gruyère, Raclette, Sbrinz and Tilsiter cheese. Lait 77:91-100

Cattaneo S, Hogenboom J, Masotti F, Rosi V, Pellegrino L, Resmini P (2008) Grated Grana Padano cheese: new hints on how to control quality and recognize imitations. Dairy Sci Technol 88: 595-605

D'Incecco P, Gatti M, Hogenboom J, Bottari B, Rosi V, Neviani E, Pellegrino L (2016a) Lysozyme affects the microbial catabolism of free arginine in raw-milk hard cheeses. Food Microbiol 57:16-22

D'Incecco P, Limbo S, Faoro F, Hogenboom J, Rosi V, Morandi S, Pellegrino L (2016b) New insight on crystal and spot development in hard and extra-hard cheeses: association of spots with incomplete aggregation of curd granules. J Dairy Sci 99:61446156

European Commission (2009) Regulation (EC) 152/2009, laying down the methods of sampling and analysis for the official control of feed. Official Journal L94, 26/2/2009, p. 1-130.

European Commission (2011a) Implementing Regulation (EU) No 584/ 2011, approving non-minor amendments to the specification for a name entered in the register of protected designations of origin and protected geographical indications (Grana Padano (PDO)). Official Journal L160, 18/6/2011, p.65-70.

European Commission (2011b). Commission Regulation (EU) No 794/ 2011, approving amendments to the specification for a name entered in the register of protected designations of origin and protected geographical indications (Parmigiano-Reggiano (PDO). Official Journal L204/19, 9/8/2011, p.19-20.

European Council (2012) Regulation (EU) No 1151/2012, on quality schemes for agricultural products and foodstuffs. Official Journal L343, 14/12/2012, p. 1-29.

Frau M, Massane J, Rosselló C, Simal S, Canellas J (1997) Evolution of free amino acid content during ripening of Mahon cheese. Food Chem 60(4):651-657

Gatti M, Bottari B, Lazzi C, Neviani E, Mucchetti G (2014) Invited review: microbial evolution in raw-milk, long-ripened cheeses produced using natural whey starters. J Dairy Sci 97:1-19

Heems D, Luck G, Fraudeau C, Vérette E (1998) Fully automated precolumn derivatization, on-line dialysis and high-performance liquid chromatographic analysis of amino acids in food, beverages and feedstuff. J Chromatogr A 798:9-17

Horwitz W, Albert RJ (2006) The Horwitz ratio (HorRat): a useful index of method performance with respect to precision. J AOAC Int 89: $1095-1109$

Horwitz W, Kamps LR, Boyer RW (1980) Quality assurance in the analysis of foods for trace constituents. J AOAC Int 63:1344-1354

Innocente N (1997) Free amino acids and water-soluble nitrogen as ripening indices in Montasio cheese. Lait 77:359-369

ISO (2004) Accuracy (trueness and precision) of measurement methods and results - part 2: basic method for the determination of repeatability and reproducibility of a standard measurement method. ISO Standard 57252-2. International Organization for Standardization, Geneva

ISO (2008) Milk and milk products - guidance on sampling. ISO standard 707/IDF 050:2008. International Organization for Standardization, Geneva

ISO (2015) Statistical methods for use in proficiency testing by interlaboratory comparisons: ISO standard 13528. International Organization for Standardization, Geneva

Krause I, Bockhardt A, Klostermeyer H (1997) Characterization of cheese ripening by free amino acids and biogenic amines and influence of bactofugation and heat-treatment of milk. Lait 77: 101-108

Liu SQ, Holland R, Crow VL (2003) The potential of dairy lactic acid bacteria to metabolise amino acids via nontransaminating reactions and endogenous transamination. Int J Food Microbiol 86:257-269

Masotti F, Hogenboom J, Rosi V, De Noni I, Pellegrino L (2010) Proteolysis indices related to cheese ripening and typicalness in PDO Grana Padano cheese. Int Dairy J 20:352-359

Moore S, Spackman DH, Stein WH (1958) Chromatography of amino acids on sulfonated polystyrene resins: an improved system. Anal Chem 30:1185-1190

Nomura M, Kimoto H, Someya Y, Furukawa S, Suzuki I (1998) Production of $\gamma$-aminobutyric acid by cheese starters during cheese ripening. J Dairy Sci 81:1486-1491

Pellegrino L, Masotti F, Cattaneo S, Hogenboom JA, de Noni I (2013) Nutritional quality of milk proteins. In: P.L.H. McSweeney \& P.F. Fox (Eds) Advanced dairy chemistry: volume 1A: proteins: basic aspects, 4th Edn. Springer, New York, pp 515-538.

Polo C, Ramos M, Sànchez R (1985) Free amino acids by high performance liquid chromatography and peptides by gel electrophoresis in Mahon cheese during ripening. Food Chem 16: $85-96$ 
Poveda JM, Cabezas L, McSweeney P (2004) Free amino acid content of Manchego cheese manufactured with different starter cultures and changes throughout ripening. Food Chem 84:213-218

Resmini P, Hogenboom JA, Pazzaglia C, Pellegrino L (1993) Free amino acids for the analytical characterization of Grana Padano cheese. Sci Tecn Latt-Cas 44:7-19 (in Italian)

Resmini P, Pellegrino L, Pazzaglia C, Hogenboom JA (1985) Free amino acids for the quality control of Parmigiano-Reggiano cheese and particularly for the grated products. Sci Tecn Latt-Cas 36:557-592 (in Italian)

San Gabriel A, Uneyama H (2013) Amino acid sensing in the gastrointestinal tract. Amino Acids 45:451-461

Sgarbi E, Lazzi C, Iacopino L, Bottesini C, Lambertini F, Sforza S, Gatti M (2013) Microbial origin of non proteolytic aminoacyl derivatives in long ripened cheeses. Food Microbiol 15:116-120

Sousa MJ, Ardö Y, McSweeney PLH (2001) Advances in study of proteolysis during cheese ripening. Int Dairy J 11:327-345

Tansman G, Kindstedt PS, Hughes JM (2015) Crystal fingerprinting: elucidating the crystals of Cheddar, ParmigianoReggiano, Gouda, and soft washed-rind cheeses using powder x-ray diffractometry. Dairy Sci Technol 95:651-664

Toelstede S, Dunkel A, Hoffman T (2009) A series of kokumi peptides impart the long-lasting mouthfulness of matured Gouda cheese. J Agr Food Chem 57:1440-1448

Zhao CJ, Schieber A, Ganzle MG (2016) Formation of taste-active amino acids, amino acids derivative and peptides in food fermentations. Food Res Int 89:39-47 